\title{
Políticas para a educação básica: a relação entre a proposta de aceleração no Paraná e a qualidade da educação
}

\author{
Rosaria Cordeiro Bernardo Fillipi ${ }^{1}$ \\ Eliane Cleide da Silva Czernisz ${ }^{2}$ \\ Marleide Rodrigues da Silva Perrude ${ }^{3}$
}

\section{Resumo}

Este texto analisa a proposta de Aceleração de Aprendizagem no Paraná e sua relação com a qualidade do ensino. Questiona a intenção da proposta e a compreensão de qualidade nela presente. O assunto é relevante, uma vez que temos percebido uma aproximação entre as políticas para a educação básica e uma noção mercadológica da educação, cuja preocupação tem sido os índices de rendimento escolar, resultantes das avaliações em larga escala. A análise desenvolvida está ancorada em referencial materialista histórico e se utiliza de dados bibliográficos e documentais. Como resultados, podemos apontar que, se por um lado, a proposta de aceleração desenvolvida no Paraná se apresenta fortemente marcada pela lógica eficientista, por outro, constitui-se também oportunidade para repensar a aprendizagem.

Palavras-chave: Política Educacional; Qualidade do Ensino; Aprendizagem.

Policies for basic education: the relation between the proposal of acceleration in Paraná and the quality of education

\section{Abstract}

This article analyzes the proposal of Learning Acceleration in Paraná and its relationship with the quality of teaching. Such aspects lead us to question the intention of the proposals and their understanding of quality. The subject is relevant, since we have perceived an approximation between policies for basic education and a marketing notion of education, whose concern has been the rates of school performance, resulting from large-scale. The analysis developed is anchored in historical materialism and uses bibliographical and documentary data. As results, we can show that, if on the one hand the proposal of acceleration developed in Paraná is strongly marked by the efficiency logic, on the other, it is also an opportunity to rethink the learning.

Keywords: Educational Policy; Quality of Teaching; Learning.

\section{Introdução}

Este texto analisa a relação estabelecida entre o Ciclo de Aceleração de Aprendizagem, desenvolvido na rede estadual do Paraná e a qualidade da educação no contexto do neoliberalismo. Cumpre esclarecer que, para nós, as políticas para a educação básica propostas

\footnotetext{
${ }^{1}$ Universidade Estadual de Londrina, Londrina - PR. E-mail: rcbsaria@gmail.com

2 Universidade Estadual de Londrina, Londrina - PR. E-mail: elianecleide@gmail.com

${ }^{3}$ Universidade Estadual de Londrina, Londrina - PR. E-mail: marleideperrude@gmail.com
} 
desde os anos de 1990 têm sido influenciadas por uma noção eficientista de educação. Percebese isso, a partir das diretrizes ideológicas do Estado-Mínimo, pelas quais o processo de gestão da educação básica foi demarcado nas reformas educacionais, sustentadas por concepções que apontaram para a modernização, a qualidade, a flexibilização, a descentralização e o controle administrativo dos resultados.

Da mesma forma como a administração pública foi criticada por sua ineficiência na gestão, levando a uma reformulação do padrão administrativo, também a escola tem sido conclamada a pensar o fluxo escolar, entendido como marca da sua eficiência e de sua qualidade. É deste lugar que ouvimos discursos favoráveis a uma escola que possibilite um fluxo dinâmico de entrada e saída de estudantes, como se o aspecto mais importante fosse o índice percentual de ingressantes e concluintes e não as condições com as quais os estudantes têm permanecido e concluído os ensinos fundamental e médio.

Não podemos deixar de considerar, também, que esta é uma boa oportunidade para os alunos que se encontram defasados em relação à série que deveriam estar estudando, desde que o trabalho pedagógico de apoio seja tão bem realizado, a ponto de possibilitar-lhes a superação de problemas de aprendizagem. No entanto, acompanhando esta lógica eficientista, vemos também sendo valorizada a ideia de uma escola capaz de formar alunos que rapidamente concluam a educação básica e ingressem no mercado de trabalho.

Tais posicionamentos têm reforçado o entendimento de que, quando a escola não possui índices de aprovação que demarquem sua eficiência, já é motivo para se desconfiar de sua possibilidade educativa e de sua qualidade. Esta visão do que deve ser a escola é substancialmente influenciada pelo sistema capitalista de produção.

Entendemos, neste texto, que, com a necessidade de corresponder às exigências de um mundo fortemente influenciado pelo mercado e pela lógica do lucro, cada vez mais se passou a exigir da escola resultados educacionais, como um produto que sintetiza o seu trabalho. Nessa direção, ocorre uma inversão. Isso porque, ao se valorizar predominantemente os resultados, deixa-se de considerar a importância do processo da aprendizagem, do que realmente deveria ser aprendido e do significado que a escola pública deveria ter nesta sociedade. Para nós, tal instituição é o local por excelência para que os estudantes aprendam os conteúdos, compreendam o mundo e nele atuem. Isso significa que a educação escolar não deveria 
corresponder apenas a uma questão de métrica, de quantitativo de rendimento acadêmico. A passagem do estudante pela escola e a aprendizagem que ele consegue nela são muito importantes e precisam ser percebidas e assimiladas, sobretudo, pelos educadores.

Esta compreensão torna-se necessária, principalmente, porque, ao redimensionar o trabalho pedagógico na perspectiva do lucro, a escola passa a ter, como objetivo, maior busca por resultados via programas que possibilitam atingir tal meta. Quando este efeito não é alcançado, passam a ser implementadas estratégias para sua obtenção. Verifica-se que este movimento tem norteado a política de desenvolvimento de ciclos de aceleração e que tem sintonia com as medidas executadas com a reforma do aparelho do Estado que visam a tornar os órgãos públicos eficientes na perspectiva gerencial.

Para compreender este processo, questionamos: Qual a intenção da proposta de Aceleração desenvolvida no Paraná e qual é o sentido da qualidade nela presente? Trata-se de uma reflexão baseada em pesquisa bibliográfica e documental que se utiliza da abordagem materialista histórica a qual possibilita compreender a realidade social partindo dos contextos: social, econômico, político e histórico, como informou Cury (1989).

Deste modo, iniciamos, comentando o desenvolvimento da política educacional no âmbito da reforma do Estado e da gestão gerencial. Passamos, na sequência, a destacar a intenção dos ciclos de aceleração e a discorrer sobre alguns modelos implementados no país, com destaque para a experiência paranaense. Finalizamos com uma reflexão sobre as orientações seguidas pela noção de qualidade e a gestão que traz a necessidade de ações corretivas como, no caso, as propostas de aceleração.

\section{A reforma do aparelho do Estado e a gestão gerencial}

A partir da década de 1990, com o Plano Diretor da Reforma do Aparelho do Estado (PDRAE), apresentado pelo Ministério da Administração e Reforma do Estado (MARE), redefiniuse o papel do Estado, que deixou de ser o responsável direto pelo desenvolvimento econômico e social na ação de produção de bens e serviços para exercer o papel de promotor e regulador deste desenvolvimento. Desde então, a educação brasileira tomou contornos alicerçados na lógica da competição do mercado, passando a ser mensurada, quantificada e padronizada. 
De acordo com Araújo e Castro (2011), é no contexto da superação da crise do sistema capitalista que se configuravam, a partir da década de 1970, e se aprofundavam na década de 1980, as propostas das medidas para melhoria da qualidade da administração, bem como do sistema judicial e político. Buscava-se uma maior governabilidade do Estado a partir das reformas, da modificação da legislação, da administração pública e das estruturas do governo central.

Abrucio (1997) comenta sobre esse período e destaca a reforma do Estado como palavra de ordem em quase todo o mundo, e o modelo gerencial no setor público ocupou espaço e se tornou a base de substituição do antigo consenso social de modelo de estado. Abrucio (1997, p. 05) destaca que os padrões gerenciais na administração pública foram iniciados em "alguns países do mundo anglo-saxão (Grã-Bretanha, Estados Unidos, Austrália e Nova Zelândia), e, depois, gradualmente, na Europa continental e Canadá".

As discussões em torno do modelo gerencial ocorreram em toda parte, salienta Abrucio, segundo o qual:

Modelos de avaliação de desempenho, novas formas de controlar o orçamento e serviços públicos direcionados às preferências dos 'consumidores', métodos típicos do managerialism, são hoje parâmetros fundamentais a partir dos quais diversos países, de acordo com as condições locais, modificam as antigas estruturas administrativas (ABRUCIO, 1997, p.05).

De acordo com Pereira (2005), a administração pública gerencial emergiu na segunda metade do século XX como resposta à crise do Estado e estratégia para enfrentar a crise fiscal, reduzir custos e tornar mais eficiente a administração dos serviços, além de servir de instrumento de proteção do patrimônio público. Algumas características básicas definem a administração pública gerencial, o foco está nos resultados, construção de um discurso de desqualificação dos funcionários públicos, propõe-se ainda a descentralização e os contratos de gestão como instrumento de controle.

A administração gerencial orienta-se para o rígido controle sobre o desempenho, e seus resultados são aferidos por indicadores e, segundo este modelo, a descentralização e a delegação de autoridade são de responsabilidade do gestor público.

Araújo e Castro (2011, p. 90) explicitam que esse modelo de gestão se apresenta como 
“[...] fórmula prática para resolver os problemas crônicos da educação pública da América Latina". As orientações para a região foram materializadas na formulação de políticas com objetivos e estratégias previamente estabelecidas. Buscou-se "[...] construir consensos regionais e conceber um projeto homogêneo de educação para todo o continente, no qual o Projeto Principal de Educação (PPE) e o Programa Educação para Todos (EPT) são exemplos “(ARAÚJO; CASTRO, 2011, p. 92).

Os estudos de Fonseca e Oliveira (2009, p.253) destacam que, já na década de 1990, foram desenvolvidas modalidades de gestão que prometiam:

[...] melhoria dos indicadores de evasão e repetência, além do rendimento dos alunos, a autonomia e a participação da família, da comunidade educacional e da sociedade em geral em decisões afetas à escola. Compreendia-se, assim, a gestão escolar eficiente como aquela capaz de produzir mais com menor custo, inclusive buscando fontes alternativas para o financiamento da escola. Enfim traduzia-se por um conjunto de mudanças e processos com certo grau de sistematização, com vistas a modificar políticas, atitudes, ideias e conteúdos curriculares, entre outros.

Desta forma, as teorias de administração gerencial, conforme Peroni (2012), não são apenas discursos, visto que também influenciam a gestão da educação. Sobre tal influência, a autora expõe: "Entendemos que há um hibridismo nas concepções e nas práticas vivenciadas pelas escolas, misturando desde os princípios do patrimonialismo e do clientelismo até a administração burocrática e a gestão gerencial" (PERONI, 2012, p.24).

Neste contexto, o modelo gerencial foi a premissa que passou a ajustar a gestão dos sistemas de ensino e das escolas. Segundo Camini (2013, p.72): "A gestão educacional e a avaliação passaram a ser enfatizadas, sustentadas num discurso descentralizador, no que se refere às ações, à divisão de responsabilidades e tarefas, porém, os processos de tomada de decisão e avaliação continuaram centralizados".

A autora elucida o desenvolvimento do sistema de avaliação na década de 1990, a partir dos avanços tecnológicos e industriais apresentados pelo país, desafiando, assim, a qualidade da educação exigida pelo mundo do trabalho, criando uma nova organização produtiva.

Nesta perspectiva, o debate em torno da gestão da escola pautou-se pela transferência, para a escola pública, do modelo de gestão empresarial. Assim, os mecanismos de 
responsabilização, descentralização, autonomia, participação, avaliação e qualidade tornaramse direcionadores essenciais para a concretização da nova perspectiva de gestão educacional.

A reforma desencadeada no Estado Brasileiro e na gestão das políticas educacionais aliouse às premissas do gerencialismo, norteando a administração das instituições públicas de maneira geral e, em particular, das escolas, que passaram a desenvolver o trabalho pedagógico sob uma lógica empresarial, meritocrática. Esta lógica, assumida pelo Estado, interferiu nas reformas estruturais da educação pública, nos seus setores financeiro, administrativo e pedagógico, que passaram a adotar padrões de produtividade, eficiência e eficácia, seguindo o discurso orientador das instituições econômicas internacionais, como o Banco Mundial, Unesco, Banco Interamericano de Desenvolvimento, entre outros, que buscam saciar seus interesses capitalistas de desenvolvimento.

É esta a lógica que passa a dar sentido à forma de ver a escola. A quantidade de estudantes que ingressam na escola e a quantidade dos que a concluem é vista como marca do desempenho escolar e como qualidade da educação ofertada por ela. Sob esse direcionamento, as redes escolares passam a adaptar as escolas com base no teor das políticas educacionais vigentes, como veremos a seguir com os Ciclos de Aceleração.

\section{Uma breve descrição dos Ciclos de Aceleração}

A política de aceleração da aprendizagem, também conhecida como ciclo de aceleração, tem sido desenvolvida no Brasil com programas ou projetos com o intuito de corrigir o fluxo para os alunos com distorção idade/ano. Tais propostas apresentam características e modelos peculiares adequados às necessidades, podendo ser uma iniciativa pública ou configurar-se como parceria público/privada, acontecendo em âmbitos municipal e estadual de ensino.

A referida aceleração foi prevista na Lei de Diretrizes e Bases da Educação Nacional (LDBEN), Lei no 9.394/96, no artigo 23 que define: “[...] alternância regular de períodos de estudos, grupos não-seriados, com base na idade, na competência e em outros critérios, ou por forma diversa de organização, sempre que o interesse do processo de aprendizagem assim o recomendar" (BRASIL, 1996, p.8). O primeiro inciso deste artigo estabelece a reclassificação do aluno, admitindo que o processo de ensino pode se dar por meio de ciclos escolares, assim como, 
se for de interesse a promoção do ensino aprendizagem, propiciar a reclassificação de alunos por diferentes motivos, inclusive para corrigir a distorção idade/ano.

No Brasil, várias unidades da federação têm aderido à política da aceleração da aprendizagem. Neste texto, mencionamos a implementação nos Estados de Minas Gerais, São Paulo, Pará e Paraná, os quais apresentam propostas diferenciadas e as utilizam na medida em que o Gestor Público queira demonstrar uma gestão eficientista, buscando enxugar os gastos com educação e melhorar os índices educacionais, com o intuito de resolver o problema de alunos em atraso escolar. A política de aceleração da aprendizagem, na maioria das vezes, é destinada a escolas periféricas e com baixo índice no IDEB (Índice de Desenvolvimento da Educação Básica), o que nos leva a deduzir que, nestas instituições, encontram-se alunos com múltiplas carências sociais, econômicas, familiares e educacionais.

Em São Paulo e Minas Gerais, a política de ciclos escolares, que vem sendo registrada desde a década de 1980, de acordo com Barretto e Mitrulis (2001), é constante na organização da educação básica, apresentando-se como: o ciclo de aceleração da aprendizagem, ciclo de alfabetização, ciclo de formação, entre outros.

Em Santarém, no Pará, conforme Souza (2007), o ciclo de aceleração da aprendizagem acontece em todo o ensino fundamental e médio nas redes municipal e estadual, em parceria público-privada, por meio do Instituto Ayrton Senna, que implementou o Programa Acelera, em 1997, e ainda atua na gestão escolar e no processo de alfabetização de Jovens e Adultos nas escolas do município.

No caso do Estado do Paraná, já houve, em diferentes períodos, a implementação dos ciclos escolares na educação básica, tendo seu marco na década de 1980, com o Ciclo Básico, uma proposta para os anos iniciais do ensino fundamental, centralizada no processo de alfabetização. Depois, na década de 1990, esta aceleração ocorreu com o Programa de Correção de Fluxo, direcionado para todo o ensino fundamental. Depois de três décadas, o ciclo de aceleração da aprendizagem retorna ao cenário da educação paranaense em 2015, segundo Filippi (2018), com o Programa de Aceleração de Estudos (PAE) para os anos finais do ensino fundamental.

Os programas de aceleração são recorrentes no cenário educacional brasileiro. Lück e Parente (2007) estudam o Programa de Aceleração da Aprendizagem adotado nacionalmente 
(1998 a 2000), tendo como foco o desenvolvimento no estado do Paraná, realizado no IPEA Instituto Pesquisa Econômica Aplicada em parceria com o Conselho Nacional de Secretários de Educação (Consed) e com o Banco Internacional de Desenvolvimento (BID) de 2000 a 2005, o qual tomou como base inicial os elevados níveis de reprovação e repetência, e segundo as autoras, estes refletem na baixa qualidade da educação.

O estudo de Lück e Parente (2007) possibilita compreender a implementação dos Programas de Aceleração, cujo objetivo tem sido a correção do fluxo escolar, a diminuição do custo aluno/ano e a melhora no índice educacional, fatores que são apresentados ao longo desse texto e constatados como resultados de avanço escolar, privilegiando-se dados numéricos. Verifica-se, no estudo das autoras, que tanto os objetivos quanto a articulação com os anos finais do ensino fundamental, estão muito próximos dos descritos no Programa de Aceleração de Estudos (2015).

No entanto, as análises de Filippi (2018, p.117) permitem compreender que o PAE teve como objetivo "corrigir a distorção idade/ano dos alunos que estão cursando os anos finais do ensino fundamental”. A autora destaca ainda que a distorção ou defasagem se caracteriza quando o aluno se mantém dois anos ou mais aquém da série que deveria estar cursando.

Nessa proposta de aceleração, para alunos do 6ㅇ e 8으 ano, foi facultado acelerar em até dois anos a sua série, mediante o trabalho com conteúdos considerados realmente essenciais em um tempo mais curto. Para Filippi (2018), a intensificação do trabalho docente e da aprendizagem, num tempo mais curto, não são fatores considerados favoráveis aos alunos visto que eles já possuem histórico de defasagem na trajetória acadêmica. Percebe-se que ao aluno resta a possibilidade de aprender, com as dificuldades que já possui, um mínimo de conteúdo que lhe favoreça avançar na série e, em um tempo menor. Para a escola, trata-se da possibilidade de impulsionar os alunos com defasagem para os anos escolares seguintes, fazendo com que não apareça em suas estatísticas os números de alunos que não progridem.

Analisando as propostas de ciclos escolares e de ciclos de aceleração da aprendizagem, percebemos que, em diferentes momentos e contextos, esta política foi implantada. Reconhecemos a importância da preocupação com a reprovação e com o abandono escolar, que têm marcado a educação brasileira, e a necessidade de se desenvolver estratégias que visem a amenizar os efeitos das reprovações. No entanto, ressaltamos que é essencial buscar as causas 
que levam a tais prejuízos acadêmicos para os estudantes e para as escolas.

Entendemos que o direcionamento que vem sendo adotado, no contexto do neoliberalismo, tem privilegiado a busca por redução numérica dos problemas de evasão e abandono, aspectos que têm simbolizado a qualidade. Na correlação entre avaliações externas e o financiamento educacional, verificamos que a gestão escolar se vale de estratégias de aquisição e apresentação de seus índices. O Estado, para conseguir alcançar os índices educacionais preestabelecidos pelos órgãos internacionais, demonstrando sua produtividade, eficiência, eficácia e qualidade, desenvolve políticas que perseguem tal retorno, como entendemos ser a política de aceleração de estudos.

\section{A qualidade norteadora do Programa de Aceleração de Estudos}

A qualidade da educação é um assunto que precisa ser analisado com bastante atenção, porque se trata de um conceito polissêmico que envolve múltiplas dimensões. Deste modo, analisar a qualidade da educação, no atual contexto capitalista, requer explicitar o que está sendo entendido como expressão deste conceito. Considerando a orientação neoliberal que tem abarcado o Estado, a educação e a compreensão do trabalho que deve ser desenvolvido pela escola, temos observado a apresentação da qualidade como relativa a resultados de desempenho estudantil nas avaliações, da classificação das escolas nos rankings divulgados pela mídia e na gestão voltada para eficiência na perspectiva de mercado.

Por essa razão, compreendemos que a análise da qualidade da educação não pode ser realizada, desprovida de uma análise da orientação que a fundamenta. Quando debatemos a qualidade da educação, precisamos nos remeter ao conceito e deixá-lo claro. No caso das escolas, é necessário pensar ainda como estas são definidas e fundem as práticas de gestão e de qualificação da escola pública. Cumpre salientar que é, no contexto da reestruturação produtiva, do padrão de organização e das mudanças no papel do Estado capitalista, que faz sentido tratar a qualidade da educação, identificando as contradições que este termo suscita, compreendendo as perspectivas que o conceito adquire.

O termo qualidade tem suas origens no campo empresarial e detém lugar de destaque no contexto da reforma do Estado sob a lógica gerencial. A partir do Plano Diretor da Reforma 
do Aparelho do Estado, a gestão pela Qualidade Total (Total Quality Control), ocupou espaço como a "principal estratégia de gerenciamento a ser adotada pelas organizações do Estado" (PEREIRA, 1999, p.08), um modelo que foi adequado ao setor público ${ }^{4}$. O autor salienta que, no início da década de 1990, houve uma primeira tentativa de introdução da gestão de qualidade na administração federal brasileira, que, porém, não foi bem-sucedida, pois, não havia uma definição das diferenças entre as administrações pública e privada e faltava autonomia para os altos funcionários para a construção de um modelo global de reforma.

Conforme verificamos a partir de Pereira (1999), entendemos que foi no contexto da Reforma Gerencial de 1995 que a perspectiva empresarial da qualidade passou a orientar a administração pública, alterando a função do Estado de provedor para regulador, enxugando suas funções sociais, contribuindo para a construção de um Estado 'Mínimo'.

Ora, a qualidade da educação, apesar de toda amplitude inspirada pelo mercado, é muito mais abrangente do que podemos imaginar, esclarecimento que é plenamente compreensível quando tomamos a discussão de Dourado, Oliveira e Santos (2007). Para os autores: "Os conceitos, as concepções e as representações sobre o que vem a ser uma Educação de Qualidade alteram-se no tempo e espaço, especialmente se considerarmos as transformações mais prementes da sociedade contemporânea [...]" (DOURADO, OLIVEIRA, SANTOS, 2007, p.3). É importante destacar que a qualidade exige uma análise profunda sobre as tramas do tecido que a envolve.

$\mathrm{Na}$ escola, a análise da qualidade requer verificar, como foi destacado por Dourado, Oliveira e Santos, a formação dos professores, a carreira e salários, a organização e estrutura escolares. Deve também ser vista dentro do plano de governo da mantenedora, pois é pela análise que a mesma faz de sua importância e concepção no plano governamental que teremos condições de, realmente, compreender suas intenções e até seus resultados. Ainda precisa ser verificada em relação ao projeto social e econômico mais amplo que também gesta em seu interior projetos educativos e formas de organização e gestão escolar que levam ao alcance de metas de seu interesse.

Esta compreensão é muito importante quando verificamos que a qualidade se orienta

\footnotetext{
${ }^{4}$ Pereira (1999) cita o Programa Brasileiro da Qualidade e Produtividade - PBQP que atingiu êxitos importantes,
} principalmente, no setor industrial que foi adaptado para atender às especificidades do setor público. 
pelo mercado e assume um sentido que não corresponde àquele que prioriza a educação pública com condições significativas para sua realização. A qualidade a que nos referimos aqui envolve o trabalho com os conteúdos elaborados, que são herança da humanidade. Diz respeito a escolas em boas condições, com professores bem formados, recebendo salários justos. Tais características são muito diferentes quando avaliamos que a educação de qualidade, na lógica do mercado, prioriza a concorrência e o ranqueamento entre instituições, o eficientismo de redes escolares, escolas e profissionais e transforma a formação em um índice e o professor e o aluno em número. Entendemos que esta inclinação para o mercado tem levado ao interesse pelos índices educacionais oportunizados por testes e exames de larga escala, um forte indício do formato assumido pela educação no neoliberalismo.

Neste sentido, o Estado passa a aferir seu processo educativo pelo crivo das avaliações externas, definidas pela noção de qualidade total. Por meio de provas na disciplina de Língua Portuguesa e Matemática, o processo metodológico das avaliações em larga escala, que ocorre em média a cada dois anos, acontece nos anos iniciais e finais de cada etapa da educação básica. Além disso, consideram-se, ainda, os números de reprovação e aprovação, lembrando que a aprovação por conselho de classe final soma-se ao número de reprovação. Estes indicadores é que vão gerar o índice educacional de cada escola, polo educacional, cidade, Estados e Distrito Federal e o Índice de Desenvolvimento da Educação Básica (IDEB).

Os índices educacionais no Brasil são obtidos pelo Instituto Nacional de Estudos e Pesquisas Educacionais Anísio Teixeira (INEP), que é uma autarquia federal vinculada ao Ministério da Educação (MEC), e tem como finalidade promover estudos e pesquisas sobre o Sistema Educacional Brasileiro e avaliá-lo para subsidiar a formulação e implementação de políticas públicas para a área educacional, a partir de parâmetros de qualidade e equidade.

As avaliações em larga escala ou externas, porém, têm apresentado fragilidades e lacunas tanto em seu processo quanto nos seus resultados, por exibir contradições quanto à sua finalidade de promover a melhoria da qualidade da educação. Isso porque, estas avaliações utilizam questões baseadas em conteúdos pré-definidos, além de serem elaboradas de maneira aleatória, concebendo, de forma simbólica, o processo de ensino-aprendizagem e as demandas peculiares de cada escola. Ademais, na apresentação dos resultados, como já mencionado, considera-se o número de alunos aprovados e reprovados incluindo os que abandonam a escola 
ou dela se evadem - desafio de caráter social que assola a educação brasileira. Assim, as avaliações externas tendem a causar efeitos colaterais à educação pública, pois seus resultados geram uma classificação, criando rankings das escolas, o que, nem sempre auxilia a melhoria da qualidade.

Suscitando a comparação e a competitividade entre as instituições educacionais e, até mesmo, entre os governos (estaduais e municipais), além de promover a especulação da opinião pública, estes resultados obtidos nestas avaliações em larga escala têm gerado até "concursos" que premiam gestores e professores das escolas que se encontram no topo da lista, cumprindo as metas estabelecidas pelo Instituto Nacional de Estudos e Pesquisas Educacionais Anísio Teixeira (INEP).

Tal situação vem afetando negativamente a educação pública brasileira, já que se tem buscado a qualidade por meio de mecanismo de exclusão, pois tais métodos não possibilitam "insumos" para que as escolas de baixo rendimento tenham subsídios que as auxiliem a superar suas dificuldades. A divulgação destes resultados por escola conforma o serviço público à lógica do mercado e não tem resolvido a questão da qualidade pretendida, porque, em geral, as metas estabelecidas pelo governo são inatingíveis pela forma como estão sendo articuladas as políticas educacionais de financiamento e incentivo à educação pública.

Mesmo entendendo que o estado promove avaliações de larga escala para cumprir seu papel regulador, visando ao controle social que lhe cabe na fatia de encargo, destacamos que a avaliação externa, em vez de propiciar alterações para a melhoria do ensino, acaba por segregar os espaços escolares, visto que busca separar os bons alunos dos que estão em defasagem, sem Ihes dar suporte para alcançarem sucesso.

O financiamento educacional depende dos índices aferidos pelas avaliações externas, que pontuam a credibilidade de desenvolvimento educacional no Brasil e propiciam novos aportes junto aos órgãos internacionais para o país ou a renovação dos já existentes. Cumpre salientar, porém, que o funcionamento do investimento educacional no Brasil é comandado pela trilogia custo-aluno-ano e movido pela composição educacional: reprovação, evasão e abandono escolar, erradicação do analfabetismo e conclusão do Ensino Fundamental e Médio, em idade própria definida pelas Leis $\mathrm{n}$ - $11.274 / 2006$ e $\mathrm{n}$ - $11.330 / 2006$. Cumpre lembrar que tais Leis determinam que o Distrito Federal, os Estados, os Municípios e, supletivamente, a União, devem 
matricular todas as crianças, a partir dos seis anos de idade no Ensino Fundamental, isto é, no Ensino Fundamental de 9 anos.

O presente modelo de financiamento educacional é resultado de inúmeras alterações e de diferentes legislações que nortearam a distribuição de valores que, no primeiro momento, atenderam apenas ao Ensino Fundamental. Como havia necessidade de se considerar outras demandas, passou a contemplar toda a Educação Básica, que está dividida em três etapas: educação infantil (subdividida em creche e pré-escola); o ensino fundamental de nove anos e o ensino médio. Em função de tal divisão, cabe aos municípios, estados e à União a responsabilidade financeira pela manutenção da educação básica brasileira.

Destacamos que o Fundo de Manutenção e Desenvolvimento da Educação Básica (FUNDEB) promoveu, para alguns estados, um aumento significativo no percentual de verba para educação, já que o cálculo é baseado no número de matrículas e os estados que não arrecadam o valor mínimo estipulado por lei recebem uma complementação com a intenção de garantir o "mínimo de qualidade" para educação brasileira. Isso porque esta enfrenta desafios em relação ao acesso, à permanência e ao sucesso escolar, justificados, geralmente, por aspectos sociais, econômicos, políticos e culturais, fatores que, como se sabe, influenciam o desempenho escolar do aluno, podendo prejudicar, muitas vezes, o alcance da pretendida qualidade.

\section{Considerações finais}

Iniciamos este texto com o objetivo de analisar a relação estabelecida entre o Ciclo de Aceleração de Estudos desenvolvido no Estado do Paraná e a qualidade da educação. Constatamos que vivemos em uma sociedade capitalista guiada por ideais neoliberais, que disseminam o princípio de sucesso ou fracasso como parte do esforço individual e emprega a lei da meritocracia presente na sociedade dividida em classes em que imperam os interesses do capital. Em vista disso, vigora na sociedade uma crença na promoção individual e na provável ascensão de classe social possibilitadas por uma educação que, em geral, vem atendendo às exigências capitalistas.

Apresentada como primordial para o desenvolvimento da nação, a educação, por vezes proclamada como redentora dos problemas sociais, desenvolve-se norteada por uma noção de 
qualidade que valoriza um sistema de avaliação que prioriza os índices de desempenho e opera, ampliando a desigualdade entre as escolas, pois, excluindo veladamente os que não se enquadram neste sistema de méritos, não tem possibilitado a melhora da educação, mas tem buscado atender às necessidades do mercado.

As avaliações externas, atreladas à noção de qualidade de mercado, têm entendido o investimento educacional como uma relação de custo-aluno-ano, levando o acesso, a permanência e a terminalidade educacional a serem tratados pela quantidade e não pela qualidade. Neste sentido, a reprovação escolar é um empecilho a ser superado pelos governos, pois mancha a proficiência das escolas e, como alternativa para se tentar resolver este problema e aliviar financeiramente o Estado, os governos vêm implementando políticas de ciclo escolares que visam a acelerar a aprendizagem, com vistas a minimizar os efeitos da reprovação na educação, sem, contudo, combater suas causas, uma característica do PAE desenvolvido no Paraná.

Entendemos que, nesse sentido, a reprovação deve ser repensada como obstáculo que distorce a direção que deveria ter a escola, qual seja, a de uma instituição que possibilite que os alunos aprendam e aprimorem seu conhecimento visando ao seu pleno desenvolvimento humano e ao exercício da cidadania. Em contrapartida, a política educacional de reclassificação de alunos em defasagem idade/ano possibilita que muitos deles encontrem a oportunidade de continuar e concluir seus estudos, por vezes, modificando sua condição de subsistência frente à desigualdade social sofrida.

Pleiteamos que a escola tenha bons professores, com formação inicial adequada e com formação continuada constante. Também se faz necessário que sejam considerados um plano de carreira e salários condizentes com a função e exercício do trabalho docente, um aspecto que foi defendido em ocasião das defesas do Plano Nacional de Educação (Lei 13.005/2014) e que, no atual governo, foi abandonado. E defendemos ainda, que as escolas possam contar com infraestrutura adequada, possibilitando condições de trabalho decente aos profissionais que nelas se engajam a cada dia na tarefa de educar, para que a educação ofertada transpasse o limite do acesso, permanência e conclusão, e que oportunize uma educação emancipatória, reforçando a importância da educação como direito, aspecto que tem sido negado pela escola norteada por interesses neoliberais. 


\section{Referências}

ABRUCIO, F. L. O impacto do modelo gerencial na administração pública: um breve estudo sobre a experiência internacional recente. Cadernos ENAP, n.10. Brasília, DF, p.1-50, 1997. Disponível em:

http://repositorio.enap.gov.br/bitstream/1/556/1/O\%20impacto\%20do\%20modelo\%20gerenci al\%20na\%20Administra\%C3\%A7\%C3\%A3o\%20P\%C3\%BAblica.pdf Acesso em: 07 abr. 2018.

ARAÚJO, S.; CASTRO, A. M. D. A. Gestão educativa gerencial: superação do modelo burocrático? Ensaio: Avaliação de Políticas Públicas. Educ., Rio de Janeiro, v.19, n.70, p.81-106, jan./mar. 2011. Disponível em: http://www.scielo.br/pdf/ensaio/v19n70/v19n70a06.pdf Acesso em: 07 abr. 2018.

BARRETTO, E. S. S.; MITRULIS, E. Trajetória e desafios dos ciclos escolares no país. Revista de Estudos Avançados. São Paulo, v.15, n.42, p.103-140, maio/ago. 2001.

BRASIL. Ministério da Educação. Lei no 9.394, de 20 de dezembro de 1996. Estabelece as diretrizes e bases da educação nacional. Disponível em:

http://www.camara.gov.br/sileg/integras/152182.pdf. Acesso em: 30 mai. 2018.

BRASIL. Ministério da Educação. Lei no 11.274, de 6 de Fevereiro de 2006. Altera a redação dos arts. 29, 30, 32 e 87 da Lei $n^{\circ}$ 9.394, de 20 de dezembro de 1996, que estabelece as diretrizes e bases da educação nacional, dispondo sobre a duração de 9 (nove) anos para o ensino fundamental, com matrícula obrigatória a partir dos 6 (seis) anos de idade. Disponível em: http://www.planalto.gov.br/ccivil_03/_ato2004-2006/2006/lei/l11274.htm. Acesso em: 30 mai. 2018.

BRASIL. Ministério da Educação. Lei no 11.330, de 25 de julho de 2006. Dá nova redação ao § $3^{\circ}$ do art. 87 da Lei n 9.394, de 20 de dezembro de 1996. Disponível em: https://www.planalto.gov.br/ccivil_03/_Ato2004-2006/2006/Lei/L11330.htm. Acesso em: 30 mai. 2018.

BRASIL. Ministério da Educação. Planejando a próxima década: conhecendo as 20 metas do Plano Nacional de Educação. Ministério da Educação/Secretaria de Articulação com os Sistemas de Ensino (MEC/Sase): Brasília, DF, 2014.

CAMINI, L. Política e gestão educacional brasileira: uma análise do plano de desenvolvimento da educação/plano de metas compromisso todos pela educação (2007-2009). São Paulo: Outras Expressões, 2013.

CURY, C. R. J. Educação e contradição: elementos metodológicos para uma teoria crítica do fenômeno educativo. São Paulo. Cortez: Autores Associados, 1989.

DOURADO, L. F.; OLIVEIRA, J. F.; SANTOS, C. A. A qualidade da educação: conceitos e 
definições. [série documental: textos para discussão]. Brasília, DF, v.24, n.22, p.5-34, 2007.

FILIPPI, R. C. B. Programa de Aceleração de Estudos no Paraná: desafios e perspectivas para a qualidade da educação. 2018. 139f. Dissertação (Mestrado em Educação) - Programa de PósGraduação em Educação da Universidade Estadual de Londrina, Londrina, 2018.

FONSECA, M.; OLIVEIRA, J. F. O. A gestão escolar no contexto das recentes reformas educacionais brasileiras. RBPAE, v.25, n.2, p.233-246, mai./ago. 2009. Disponível em: http://www.educacao.mppr.mp.br/arquivos/File/gestao_democratica/kit5/a_gestao_escol ar_no_contexto_das_recentes_reformas.pdf Acesso em: 30 mai. 2018.

LÜCK, H.; PARENTE, M. A aceleração da aprendizagem para corrigir o fluxo escolar: o caso do Paraná [texto para discussão, no 1.274]. Brasília: Ipea, 2007.

PARANÁ. Secretaria de Estado de Educação. Programa de Aceleração de Estudo: orientações pedagógicas. Curitiba: SEED/DEB, 2015.

PEREIRA, L. C. B. Reflexões sobre a reforma gerencial brasileira de 1995. Revista do Serviço Público. n.4, p.05-29, out-dez, 1999. Disponível em:

https://revista.enap.gov.br/index.php/RSP/article/viewFile/354/360. Acesso em: 11 mai. 2018.

PEREIRA, L. C. B. Gestão do setor público: estratégia e estrutura para um novo Estado. In:

PEREIRA, L. C. B.; SPINK, P. (org.). Reforma do Estado e administração pública gerencial. 7.ed. Rio de Janeiro: FGV, 2005.

PERONI, V.M. V.A gestão democrática da educação em tempos de parceria entre o público e o privado. Revista Pro-Posições, Campinas, v.23, n.2 (68), p.19-31, maio/ago. 2012. Disponível em: http://www.scielo.br/pdf/pp/v23n2/a03v23n2.pdf Acesso em: 07 abr. 2018.

SOUZA, M. F. M. Política de correção de fluxo: um estudo avaliativo do Programa de Aceleração da Aprendizagem em Santarém - Pará. 2007. 177f. Tese (Doutorado em Educação) - Programa de Pós-Graduação em Educação da Faculdade de Ciências e Letras, Universidade Estadual Paulista, Araraquara, 2007.

Recebido em junho 2019.

Aprovado em junho 2020. 